\title{
Comparison of two convective warming systems during major abdominal and orthopedic surgery
}

[Comparaison de deux systèmes de chauffage par convection pendant des chirurgies abdominales et orthopédiques majeures]

Karl Wagner MD, Erika Swanson, Clifford J. Raymond BS, Charles E. Smith MD FRCPC

Purpose: Convective warming is routinely employed to maintain perioperative normothermia. However, due to differences in nozzle temperature and air flow of the power units, there are clinically relevant differences in heat transfer among convective warming systems. The purpose of this study was to evaluate the use of a quieter, convective warming system (WarmAir, sound pressure level $49 \mathrm{dba}$, air flow $35 \mathrm{cfm}$ ). The WarmAir system was compared to the standard, higher air flow system (Bair Hugger Model 750, sound pressure level $55 \mathrm{dba}$, air flow $48 \mathrm{cfm}$ ) with regards to temperature outcome.

Methods: Patients undergoing general anesthesia for major abdominal and orthopedic surgery were randomized into one of two groups: WarmAir or Bair Hugger. Both groups received an upper body, convective blanket using coverage appropriate for the given surgical procedure. Convective warming, at the high setting, was started after prepping and draping, and distal esophageal or nasopharyngeal temperature was measured intraoperatively. Sublingual temperature was measured preoperatively and on admission to the postanesthesia care unit.

Results: The WarmAir $(n=89)$ and Bair Hugger $(n=95)$ groups were similar with respect to age, gender, body mass index, ASA status, fluid balance, and duration of surgery. There was no difference in temperature outcomes between groups. In the WarmAir group, preoperative, lowest intraoperative, end of surgery, and postanesthesia care unit admission temperatures were (means $\pm S D$ ); $36.3 \pm 0.5,35.4 \pm \mathrm{I} . \mathrm{I}, 36.4 \pm 0.7$, and $36.4 \pm 0.6^{\circ} \mathrm{C}$, respectively. Corresponding temperatures in the Bair Hugger group were; $36.3 \pm 0.6,35.6 \pm$ I.0, $36.5 \pm 0.6$, and $36.4 \pm 0.5^{\circ} \mathrm{C}$, respectively.

Conclusion: Despite differences in heating characteristics, both convective warming systems were effective in maintain- ing perioperative normothermia in patients undergoing major abdominal and orthopedic surgery. Therefore, choice of warming system is dependent on other factors such as ergonomics and cost.

CAN J ANESTH 2008/55: $6 /$ pp 358-363

Objectif : Le chauffage par convection est habituellement utilisé pour maintenir la normothermie périopératoire. Toutefois, en raison de différences au niveau de la température du bec et du débit d'air des blocs d'alimentation, il existe des différences significatives d'un point de vue clinique quant au transfert de chaleur lorsque l'on compare différents systèmes de chauffage par convection. L'objectif de cette étude était d'évaluer l'utilisation d'un système de chauffage par convection plus silencieux (WarmAir, niveau de pression acoustique $49 \mathrm{dba}$, débit d'air $35 \mathrm{cfm}$ ). Le système WarmAir a été comparé au système standard, avec un débit d'air plus élevé (Bair Hugger Model 750, niveau de pression acoustique $55 \mathrm{dba}$, débit d'air 48 (fm), en ce qui a trait au niveau de la température atteinte.

Méthode: Des patients subissant une anesthésie générale lors de chirurgies abdominales ou orthopédiques majeures ont été randomisés en deux groupes: WarmAir ou Bair Hugger. Les deux groupes ont reçu une couverture chauffante pour le haut du corps couvrant une surface adaptée à l'intervention chirurgicale en question. Le chauffage par convection, au niveau de réglage le plus élevé, a été débuté après le badigeonnage et la pose des champs, et la température oesophagienne distale ou naso-pharyngée a été mesurée pendant l'opération. La température sublinguale a

From the Department of Anesthesiology, MetroHealth Medical Center, Case Western Reserve University School of Medicine, Cleveland, Ohio, USA.

Address correspondence to: Dr. Charles Elliot Smith, Department of Anesthesia, MetroHealth Medical Center, 2500 MetroHealth Drive, Cleveland, Ohio 44109, USA. Phone: 216-778-3616; Fax: 216-778-5378; E-mail: csmith@metrohealth.org

Financial support: The study was supported by: departmental sources; the Chester Scholar Foundation, MetroHealth Medical Center, Cleveland, Ohio; and Cincinnati Sub-Zero, Cincinnati, Ohio.

None of the authors has competing interests or financial interests in any of the medical devices evaluated in the study.

The study was presented at the MetroHealth Medical Center, Chester Scholar Fair, Cleveland, Ohio, August, 2007.

Accepted for publication January 3, 2008.

Revision accepted February 22, 2008. 
été mesurée avant l'opération et lors de l'admission à la salle de réveil.

Résultats : Les groupes WarmAir $(n=89)$ et Bair Hugger $(n=$ 95) étaient semblables au niveau de l'âge, du sexe, de l'indice de masse corporelle, de l'état physique selon I'ASA, de l'hydratation et de la durée de la chirurgie. Il n'y a pas eu de différences dans les températures atteintes entre les deux groupes. Dans le groupe WarmAir, les températures préopératoire, au plus bas pendant l'opération, à la fin de la chirurgie et à l'admission à la salle de réveil étaient de (moyennes $\pm E T$ ) : 36,3 \pm 0,5, 35,4 $\pm I, I, 36,4 \pm 0,7$, et $36,4 \pm 0,6^{\circ} \mathrm{C}$, respectivement. Les températures correspondantes dans le groupe Bair Hugger étaient de : 36,3 \pm 0,6, 35,6 \pm I,0, $36,5 \pm 0,6$, et $36,4 \pm 0,5^{\circ} \mathrm{C}$, respectivement.

Conclusion: Malgré des différences dans les caractéristiques de chauffage, les deux systèmes de chauffage par convection à l'étude ont été efficaces pour maintenir la normothermie périopératoire chez les patients subissant des chirurgies abdominales et orthopédiques majeures. Dès lors, le choix d'un système de chauffage dépend d'autres facteurs tels que l'ergonomie et le coût.

$\mathrm{H}$ YPOTHERMIA (core temperature $<36^{\circ} \mathrm{C}$ ) is common during general anesthesia, owing to factors such as: impaired thermoregulation, redistribution of heat from the core to the periphery, heat loss to a cold operating room, and infusion of unwarmed fluids., ${ }^{1,2}$ Consequences of perioperative hypothermia include: adrenergic activation, myocardial ischemia, thermal discomfort, decreased drug metabolism, increased blood loss and transfusion requirements, wound infections, adverse cardiac outcomes, prolonged recovery room stay, and increased costs. , $^{1,3-8}$

Because of the major, adverse consequences of perioperative hypothermia, it has become routine practice, at our institution to actively warm patients undergoing major surgeries with convective warming using the Bair Hugger system (Model 750, Arizant Healthcare Inc., Eden Prairie, MN, USA). The system prevents further cutaneous heat loss and transfers heat across the skin surface. However, due to excessive noise and air flow of the system (sound pressure level $55 \mathrm{dba}$, air flow $48 \mathrm{cfm})^{\mathrm{A}}$, some surgeons at our hospital request that the warming unit be turned off. This issue led us to search for a quieter convective warming system with reduced air flow. There is concern, however, that convective warming systems with lower air flow would

A Bair Hugger Model 750 Temperature Management Unit Operator's Manual. Arizant Healthcare Inc., Eden Prairie, MN, USA have lower heat transfer, would be unable to transfer sufficient heat to the patient, and would be associated with worsened temperature outcomes. ${ }^{9,10}$

The purpose of this study was to evaluate the use of a quieter, convective warming system (WarmAir, Cincinnati Sub-Zero, Cincinnati, OH, USA) with sound pressure level $49 \mathrm{dba}$ and air flow $35 \mathrm{cfm}^{\mathrm{B}}$ The WarmAir system was compared to the standard, higher air flow, Bair Hugger warming system with regards to maintenance of intraoperative normothermia.

\section{Methods}

The Institutional Review Board approved the protocol, and written, informed consent was obtained from the patients prior to surgery. The patients in the study were American Society of Anesthesiology physical status I-III adults who were undergoing elective, major abdominal and orthopedic surgery that was scheduled to last $>60 \mathrm{~min}$. The exclusion criteria were: age $<18$ or $>85 \mathrm{yr}$; history of malignant hyperthermia; surgery duration $<60 \mathrm{~min}$; use of regional anesthesia instead of general; and preoperative temperature $>38^{\circ} \mathrm{C}$ or $<35^{\circ} \mathrm{C}$. The patients were identified through the daily surgical schedule. A random, number generating algorithm was used to allocate patients to either the treatment group (WarmAir Model 135 with FilteredFlo upper body blanket, high setting $43.3 \pm 4^{\circ} \mathrm{C}$ ) or to the standard warming group (Bair Hugger Model 750 with upper body blanket model 522 , high setting $43 \pm 1.5^{\circ} \mathrm{C}$ ). Coverage was appropriate for the given surgical procedure (approximately $18 \pm 6 \%$ body surface area). ${ }^{11}$ Active warming was started after prepping and draping and discontinued at the end of surgery. Fluids were infused, intraoperatively, via a fluid warmer.

All patients underwent general anesthesia. Choice of anesthetic agent was at the discretion of the anesthesiologist and not dictated by protocol. Anesthetic gases were delivered via a tracheal tube or by means of a laryngeal mask airway (LMA) using a circle system, heat and moisture exchanger, and $\mathrm{CO}_{2}$ sodalime absorber. The ambient temperature was set at $21^{\circ} \mathrm{C}$.

Sublingual temperatures were measured, preoperatively, and on admission to the postanesthesia care unit (PACU), with an electronic thermometer (IVAC Temp Plus II thermistor, IVAC Corp., San Diego, CA, USA). During all measurements, sublingual placement and mouth closure was carried out by nurses experienced in the use of this device. Following induction, until the end of surgery, distal esopha-

B WarmAir Operation \& Technical Manual for Model 135 Warming Units. Cincinnati Sub-Zero Products, Inc, Cincinnati, $\mathrm{OH}$, USA. 
TABLE I Patient and cost information

\begin{tabular}{|c|c|c|}
\hline & WarmAir FilteredFlo & Bair Hugger \\
\hline Age, yr & $48 \pm 15$ & $46 \pm 14$ \\
\hline Male & $25(28 \%)$ & $33(35 \%)$ \\
\hline Female & $64(72 \%)$ & $62(65 \%)$ \\
\hline Weight, kg & $89 \pm 25$ & $87 \pm 25$ \\
\hline Height, m & $1.69 \pm 0.21$ & $1.67 \pm 0.11$ \\
\hline Body mass index & $31.5 \pm 8.3$ & $31.2 \pm 8.4$ \\
\hline \multicolumn{3}{|l|}{ Surgical service } \\
\hline Gynecology & $36(40 \%)$ & $28(29 \%)$ \\
\hline General & $31(35 \%)$ & $34(36 \%)$ \\
\hline Laparoscopy used & $18 / 31(58 \%)$ & $20 / 34(59 \%)$ \\
\hline Orthopedics & $22(25 \%)$ & $33(35 \%)$ \\
\hline \multicolumn{3}{|l|}{ ASA physical status } \\
\hline I & $2(2 \%)$ & $10(10 \%)$ \\
\hline II & $57(64 \%)$ & $56(59 \%)$ \\
\hline III & $30(34 \%)$ & $33(35 \%)$ \\
\hline Anesthesia duration, min & $187 \pm 73$ & $185 \pm 72$ \\
\hline \multicolumn{3}{|l|}{ Airway tube } \\
\hline Endotracheal & $79(89 \%)$ & $80(84 \%)$ \\
\hline Laryngeal mask & $10(11 \%)$ & $15(16 \%)$ \\
\hline Surgery duration, min & $131 \pm 70$ & $127 \pm 63$ \\
\hline Estimated blood loss, $\mathrm{mL}$ & $177 \pm 379$ & $154 \pm 225$ \\
\hline Crystalloid, $\mathrm{mL}$ & $1948 \pm 962$ & $1886 \pm 977$ \\
\hline Hextend, $\mathrm{mL}$ & $790 \pm 495, n=10$ & $747 \pm 257, n=19$ \\
\hline Red blood cells $(n)$ & 3 & 4 \\
\hline Cell saver $(n)$ & 2 & 0 \\
\hline \multicolumn{3}{|l|}{ Cost (US \$) } \\
\hline Upper body blanket & $\$ 7.00$ & $\$ 6.63$ \\
\hline Power unit and hose & $\$ 1200$ & $\$ 1499$ \\
\hline
\end{tabular}

Data are means \pm SD or numbers of patients. There were no significant differences between groups.

geal (tracheal intubated patients) or nasopharyngeal (LMA patients) temperatures were measured using an 18 or $9 \mathrm{Fr}$ esophageal stethoscope with thermistor (400 series, Lifesound, Novamed, Rye, NY, USA). The temperature was continuously displayed (Philips Medical Systems, Boeblingen, Germany) and stored in an automated system (CompuRecord, Philips). Postanesthesia care unit vital signs were recorded within ten minutes of admission to the PACU.

\section{Statistical considerations}

With a sample size of 172 patients, and assuming the true difference between the control and the treatment groups was $0.25^{\circ} \mathrm{C}$, with a standard deviation of $0.5^{\circ} \mathrm{C}$; the probability was $90 \%$ that the study would detect a treatment difference at a two-sided, $5 \%$, significance level. The target enrolment was 200 patients, in order to account for exclusions. Temperature data (reported as means $\pm \mathrm{SD}$ ) were compared between groups using two-way ANOVA. Ninety-five percent confidence limits were calculated using means \pm 1.96
TABLE II Temperature data and PACU vital signs

\begin{tabular}{|c|c|c|c|}
\hline & $\begin{array}{l}\text { WarmAir } \\
\text { FilteredFlo }\end{array}$ & Bair Hugger & P Value \\
\hline \multicolumn{4}{|l|}{ Temperature, ${ }^{\circ} \mathrm{C}$} \\
\hline Preoperative & $36.3 \pm 0.5$ & $36.3 \pm 0.6$ & \multirow[t]{2}{*}{0.57} \\
\hline $95 \%$ confidence limits & $36.2-36.4$ & $36.2-36.4$ & \\
\hline 10 min after induction & $36.1 \pm 0.5$ & $36.1 \pm 0.6$ & \multirow[t]{2}{*}{0.33} \\
\hline $95 \%$ confidence limits & $36.0-36.2$ & $36.0-36.2$ & \\
\hline Lowest intraoperative & $35.4 \pm 1.1$ & $35.6 \pm 1.0$ & \multirow[t]{2}{*}{0.28} \\
\hline $95 \%$ confidence limits & $35.2-35.6$ & $35.4-35.8$ & \\
\hline End of surgery & $36.4 \pm 0.7$ & $36.5 \pm 0.6$ & \multirow[t]{2}{*}{0.52} \\
\hline $95 \%$ confidence limits & $36.3-36.5$ & 36.4-36.6 & \\
\hline PACU & $36.4 \pm 0.6$ & $36.4 \pm 0.5$ & \multirow[t]{2}{*}{0.90} \\
\hline $95 \%$ confidence limits & $36.3-36.5$ & $36.3-36.5$ & \\
\hline \multicolumn{4}{|c|}{$P A C U$ admission vital signs } \\
\hline $\begin{array}{l}\text { Systolic blood } \\
\text { pressure }(\mathrm{mmHg})\end{array}$ & $140 \pm 19$ & $137 \pm 19$ & 0.77 \\
\hline $\begin{array}{l}\text { Diastolic blood } \\
\text { pressure }(\mathrm{mmHg})\end{array}$ & $69 \pm 13$ & $69 \pm 14$ & 0.87 \\
\hline Pulse $\left(\min ^{-1}\right)$ & $87 \pm 15$ & $90 \pm 16$ & 0.28 \\
\hline Respirations $\left(\min ^{-1}\right)$ & $16 \pm 4$ & $17 \pm 4$ & 0.62 \\
\hline Oxygen saturation (\%) & $97 \pm 3$ & $98 \pm 2$ & 0.48 \\
\hline
\end{tabular}

PACU $=$ postanesthesia care unit. Data are means \pm SD and $95 \%$ confidence limits. There were no significant differences between groups.

times its standard error. Non-parametric data were compared between groups with Chi-squared analysis and Fishers Exact test. A $P$ value $<0.05$ was considered significant.

\section{Results}

Of the total 196 patients enrolled in the study, 94 were randomized to the WarmAir group and 102 were randomized to the Bair Hugger group. Twelve patients were excluded (five treatment and seven standard warming group) for the following reasons: five, change in anesthesia technique (from general to nerve block, spinal or epidural); five, change in surgical plans or duration < $60 \mathrm{~min}$; and two, ASA physical status $>3$. There were no differences between groups with respect to demographics and perioperative variables (Table I). Preoperative, after induction, lowest intraoperative, end of surgery, and PACU temperatures were similar between groups $(\mathrm{F}$ value $=0.62$, $P$-value $=0.47$, Table II) .

\section{Discussion}

Both convective warming systems were effective in maintaining perioperative normothermia in patients 
undergoing major abdominal and orthopedic surgery with general anesthesia. However, the systems did not prevent redistribution hypothermia, since temperature did fall maximally on average from $36.3 \pm 0.5^{\circ} \mathrm{C}$ to $35.4 \pm 1.1^{\circ} \mathrm{C}$ in the WarmAir group and from 36.3 $\pm 0.6^{\circ} \mathrm{C}$ to $35.6 \pm 1.0^{\circ} \mathrm{C}$ in the Bair Hugger group. We did not use active prewarming, since the study was designed to simply compare two intraoperative, convective warming strategies. Active prewarming, for approximately $30 \mathrm{~min}$ prior to induction of general anesthesia, has been shown to warm the skin surface, thereby minimizing redistribution hypothermia ${ }^{12-14}$ and enhancing any other temperature management strategy.

Convective warming systems, which consist of an electrical heater and a fan (power unit) connected to a disposable blanket via an air delivery hose, vary with respect to air flow, heat flow, and heat exchange. 9 Giesbrecht et al. ${ }^{10}$ tested convective warming systems in minimally clothed, male volunteers and found significant differences in heat transfer efficacy among systems, the magnitude, of which, approached the entire metabolic heat production of an anesthetized patient. Differences among convective warming systems are also dependent on the type of blanket used (e.g., upper $v$ s lower blanket). ${ }^{15,16}$ Brauer et al. ${ }^{9}$ tested 11 commercially available, full body, convective warming systems (including the ones used in the present study) on a copper manikin and found that heat flow of the systems ranged from 249 to $623 \mathrm{~W}$, and heat exchange ranged between 30.6 and $77.3 \mathrm{~W}$. Air flow of the Bair Hugger warming system, used in the present study, was $26.2 \mathrm{~L} \cdot \mathrm{sec}^{-1}$, considerably higher than that of the WarmAir system (16.4 L. $\left.\mathrm{sec}^{-1}\right)$, which accounted for the higher heat flow $(623 \mathrm{~W}$ vs $383 \mathrm{~W})$ and the higher heat transfer $(77$ vs $35 \mathrm{~W})$ to the copper manikin at a calculated surface temperature of $32^{\circ} \mathrm{C} .{ }^{9}$

Although there are differences in heat transfer between convective warming systems, we were unable to demonstrate any difference in temperature outcomes among patients warmed with either of the two systems. This may be owing to the fact that the clinical relevance of these heat transfer differences, measured in non-anesthetized patients or measured during bench research, cannot be easily extrapolated to the human body. Rewarming rates and heat transfer are a complex function of: initial core temperature; ambient temperature; the patients' own metabolic heat production; effects of anesthesia and neuromuscular relaxants; ongoing heat losses, and other variables such as: thermal conductivity of body tissue; density of tissue; specific heat of the patient; and the patients' body surface area and mass. ${ }^{17}$ Convective warming blankets are effective rewarming techniques because of heat transfer to the vasodilated patient, and because of a reduction in cutaneous heat loss to zero in the covered areas. It is likely that the reduction in cutaneous heat loss, together with metabolic heat production, effective intravenous fluid warming, and other heat conservation techniques (heat and moisture exchanger, covering exposed surfaces) contributes significantly to the maintenance of perioperative normothermia. ${ }^{2,17,18}$ In a randomized cross-over trial of four convective warming devices (upper body blanket) in healthy volunteers, heat transfer ranged from 8.1-17 W. ${ }^{15}$ The WarmAir FilteredFlo, upper body blanket had an intermediate amount of heat transfer $(11.3 \mathrm{~W})$. Among six, different, convective warming systems ${ }^{16}$ using lower body blankets, there were no relevant differences in heat transfer from blanket to copper manikin.

In order to justify use of a replacement convective warming system, which would be more appealing to the surgeons (less noisy, decreased air flow, and blanket "lift up"), it was necessary to compare temperature outcomes between the devices in question. The WarmAir device has a sound pressure level of $49 \mathrm{dba}$, considerably lower than the Bair Hugger sound pressure level of $55 \mathrm{dba} .{ }^{\mathrm{A}, \mathrm{B}}$ Since the decibel measuring scale is logarithmic, these differences are relevant.

Methods to enhance the effectiveness of intraoperative convective warming include: meticulous attention to warming all intravenous fluids from the start of the case, increasing ambient operating room to $>24^{\circ} \mathrm{C}$ before induction of general anesthesia, and passive insulation..$^{2,18-21}$ No attempt was made to control the type or the amount of anesthetic agent in our study, except that all patients received general anesthesia. Also, it would be expected that autonomic thermoregulation would be impaired in both groups to a similar extent. Only upper body, convective warming systems were tested. Convective warming with lower body blankets may be more effective because of larger body surface area coverage. ${ }^{22}$ Other quiet methods such as: electric heating pads, radiant heat, gel-coated circulating water mattress, carbon-fibre resistive heating, and conductive energy transfer pads may be equally or more effective as convective warming in maintaining normothermia. ${ }^{23-27}$ The study did not address the use of convective warming systems during lengthier surgeries or during surgeries associated with more significant blood loss. Further studies are required to address the use of lower air flow and heat transfer, convective warming systems in these situations. The study was not designed to detect 
significant differences in discharge times, length of hospitalization, blood loss, and infection between the two warming systems.

In summary, both the WarmAir and Bair Hugger systems were effective in ensuring normothermia, postoperatively (average temperature $36.4^{\circ} \mathrm{C}$ ). The choice of convective warming system is, therefore, dependent on other factors such as cost and ergonomics.

\section{Acknowledgements}

The authors are grateful to: Christopher Brandt, MD, for his encouragement throughout the study; anesthesia and surgical personnel at MetroHealth Medical Center, for their participation; Alfred C. Pinchak PE, $\mathrm{PhD}, \mathrm{MD}$, for data analysis; and Saied Amini PhD, MBA, JD, for statistical consultation.

\section{References}

1 Sessler DI. Mild perioperative hypothermia. N Engl J Med 1997; 336: 1730-7.

2 Patel N, Smith CE, Pinchak AC, Hagen JF. Prospective, randomized comparison of the flotem iie and hotline fluid warmers in anesthetized adults. J Clin Anesth 1996; 8: 307-16.

3 Frank SM, Higgins MS, Breslow MJ, et al. The catecholamine, cortisol, and hemodynamic responses to mild perioperative hypothermia. A randomized clinical trial. Anesthesiology 1995; 82: 83-93.

4 Frank SM, Beattie C, Christopherson R, et al. Unintentional hypothermia is associated with postoperative myocardial ischemia. The Perioperative Ischemia Randomized Anesthesia Trial Study Group. Anesthesiology 1993; 78: 468-76.

5 Kurz A, Sessler DI, Lenhardt R. Perioperative normothermia to reduce the incidence of surgical-wound infection and shorten hospitalization. Study of Wound Infection and Temperature Group. N Engl J Med 1996; 334: 1209-15.

6 Frank SM, Fleisher LA, Breslow MJ, et al. Perioperative maintenance of normothermia reduces the incidence of morbid cardiac events. A randomized clinical trial. JAMA 1997; 227: 1127-34.

7 Lenhardt R, Marker E, Goll V, et al. Mild intraoperative hypothermia prolongs postoperative recovery. Anesthesiology 1997; 87: 1318-23.

8 Fleisher LA, Metzger SE, Lam J, Harris A. Perioperative cost-finding analysis of the routine use of intraoperative forced-air warming during general anesthesia. Anesthesiology 1998; 88: 1357-64.

9 Brauer A, English MJ, Steinmetz N, et al. Efficacy of forced-air warming systems with full body blankets. Can J Anesth 2007; 54: 34-41.

10 Giesbrecht GG, Ducharme MB, McGuire JP. Compari- son of forced-air patient warming systems for perioperative use. Anesthesiology 1994; 80: 671-9.

11 Smith CE, Sidhu RS, Lucas L, Mehta D, Pinchak AC. Should patients undergoing ambulatory surgery with general anesthesia be actively warmed? The Internet Journal of Anesthesiology 2007; 12: 1-19.

12 Just B, Trevien V, Delva E, Lienhart A. Prevention of intraoperative hypothermia by preoperative skinsurface warming. Anesthesiology 1993; 79: 214-8.

13 Camus $\Upsilon$, Delva E, Sessler DI, Lienhart A. Preinduction skin-surface warming minimizes intraoperative core hypothermia. J Clin Anesth 1995; 7: 384-8.

14 Sessler DI, Schroeder M, Merrifield B, Matsukawa T, Cheng $C$. Optimal duration and temperature of prewarming. Anesthesiology 1995; 82: 674-81.

15 Brauer A, English MJ, Steinmetz N, et al. Comparison of forced-air warming systems with upper body blankets using a copper manikin of the human body. Acta Anaesthesiol Scand 2002; 46: 965-72.

16 Brauer A, English MJ, Lorenz N, et al. Comparison of forced-air warming systems with lower body blankets using a copper manikin of the human body. Acta Anaesthesiol Scand 2003; 47: 58-64.

17 Gentilello LM, Monjaes $S$. Treatment of hypothermia in trauma victims: thermodynamic considerations. J Intensive Care Med 1995; 10: 5-14.

18 Smith CE, Holbrook C, Radesic B, et al. Comparison of perioperative heating modalities in anesthetized adult patients: a prospective randomized study. Am J Anesthesiol 1998; 25: 62-8.

19 Smith CE, Gerdes E, Sweda S, et al. Warming intravenous fluids reduces perioperative hypothermia in women undergoing ambulatory gynecological surgery. Anesth Analg 1998; 87: 37-41.

20 Camus $\Upsilon$, Delva E, Cohen S, Lienhart A. The effects of warming intravenous fluids on intraoperative hypothermia and postoperative shivering during prolonged abdominal surgery. Acta Anaesthesiol Scand 1996; 40: 779-82.

21 Patel N, Smith CE, Knapke D, Pinchak AC, Hagen $J F$. Heat conservation vs convective warming in adults undergoing elective surgery. Can J Anaesth 1997; 44: 669-73.

22 Camus $\Upsilon$, Delva E, Just B, Lienhart A. Leg warming minimizes core hypothermia during abdominal surgery. Anesth Analg 1993; 77: 995-9.

$23 \mathrm{Ng} V$, Lai A, Ho $V$. Comparison of forced-air warming and electric heating pad for maintenance of body temperature during total knee replacement. Anaesthesia 2006; 61: 1100-4.

24 Wong A, Walker S, Bradley M. Comparison of a radiant patient warming device with forced air 
warming during laparoscopic cholecystectomy.

Anaesth Intensive Care 2004; 32: 93-9.

25 Brauer A, Pacholik L, Perl T, English MJ, Weyland W, Braun $U$. Conductive heat exchange with a gel-coated circulating water mattress. Anesth Analg 2004; 99 : 1742-6.

26 Negishi C, Hasegawa K, Mukai S, Nakagawa F, Ozaki $M$, Sessler DI. Resistive-heating and forced-air warming are comparably effective. Anesth Analg 2003; 96: 1683-7.

27 Grocott HP, Mathew JP, Carver EH, Phillips-Bute B, Landolfo KP, Newman MF. A randomized controlled trial of the Arctic Sun Temperature Management System versus conventional methods for preventing hypothermia during off-pump cardiac surgery. Anesth Analg 2004; 98: 298-302. 